\title{
Robust controller for an open irrigation canal prototype
}

\author{
Merabti Nardjes ${ }^{1}$, Arbaoui Faycel ${ }^{2}$, Saidi Mohamed Larbi ${ }^{3}$, Said Yahmedi ${ }^{4}$ \\ 1,2,3 Laboratory of Automation and Signals Annaba, Algeria \\ ${ }^{4}$ Laboratory of Mathematical Modeling and Numerical Simulation Annaba, Algeria
}

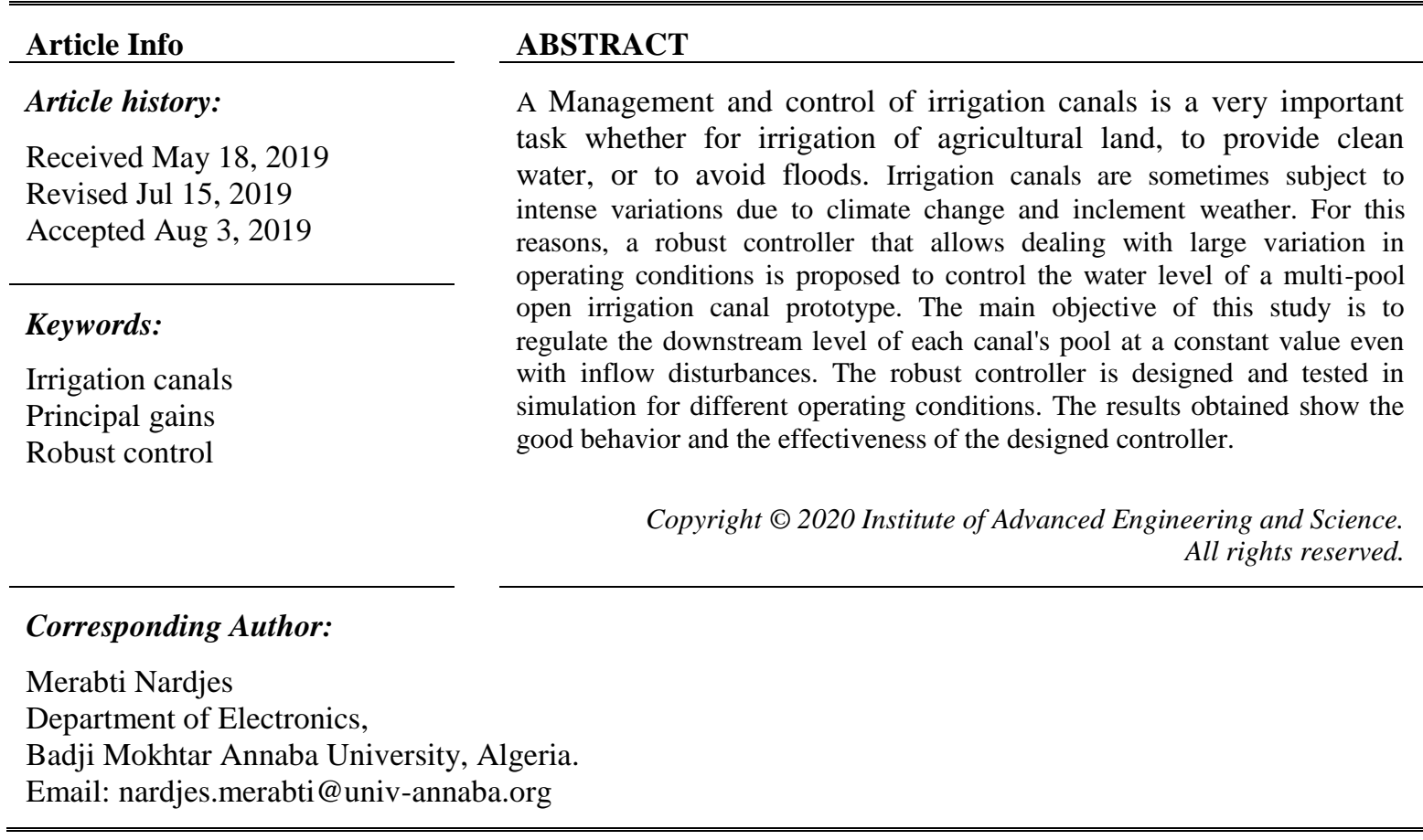

\section{INTRODUCTION}

Automatic canal control plays an important role in delivery water systems, irrigation canals are artificial systems developed to transport water from main water reservoirs to several water demanding agricultural farms during irrigation seasons.

These hydro systems exhibit large dynamic variations in their operating conditions [1] and they can generally be described as a network of pools, where each pool represents a portion of the open channel system in between two controlled hydraulic structures; water levels and flows are controlled using overshot gates located along the channels [2].

A main canal transports water from a big reservoir to the farms and controls the water flow by modifying the openings of several gates [3]. There are situated in the waterway in order to regulate discharge in relation to ongoing irrigation demands [4]. The dynamics of the water flow are characterized by delays between a control action and its effect on the levels along the canal, and they are subject to disturbances, which are mainly due to water withdrawals or weather conditions [5]; Several SISO (Single Input Single Output) and MIMO (Multi Input Multi Output) methods have been developed for canal or irrigation river systems. The experiments carried out confirm that the main basins of irrigation can have large variations in their dynamic parameters when flow or other hydraulic parameters change. The Gates are controlled and operated using suitable controllers and control strategy. A variety of control methods have been proposed and developed by researchers for modeling different flow conditions in the operation of irrigation canal systems [6]. The control of irrigation systems include upstream control, downstream control, controlled volume control, dynamic regulation, and flow rate control [7].In open irrigation canals the water dynamics are in general modeled by two nonlinear partial differential equations called the Saint-Venant equations [2], these two nonlinear partial differential equations are used to study the level and flow behavior; generally, they are not used for control design due to their complexity. Various authors propose simple models [8] such: 
state-space linear models obtained by discretization of the Saint-Venant equations [9], state-space nonlinear models [10], input-output (I/O) nonlinear models [11], or I/O linear models [12].

Different methodologies have been used for canals control. The most popular controller is based on the classical PID. Many studies have shown that these controllers seem to be unsuitable to solve the problem of effective water distribution control in irrigation canal pools with a wide range time-varying dynamical parameters [13-15], Different strategies are also described and tested on numerical simulators or laboratory canals [1,15-16], A mathematical model for robust control of an irrigation canal pool has been developed in [15].

O. Begovich et al. proposed the principle of the internal model used in this work in [18]. The considered canal is represented in the next section, where the controlled variables are the downstream levels of the first three pools and the control variables are the openings of the slide gates along of the canal [5]. The transfer function model has been explored in this paper for modeling different flow conditions in the system. It is considered as a MIMO system. The methodology was used to model different simulated flow conditions in a channel by opening and closing the upstream and downstream gates [19], the water level corresponding to different flow conditions. The transfer function model details and description are discussed in this paper.

The robust controllers are known for their ability to provide very good control of this type of system. The main objective of the controller is to regulate the downstream level of each canal's pool in spite of large inflow disturbances and time-varying dynamical parameters. The methodology is applied to solve the problem of effective water distribution control in an irrigation main canal pool [20]. This robust control method is evaluated by simulation on transfer function model for different flow conditions.

Control theory implies a three step process: system modeling, system analysis and the controller design, including selection of controller structure and control parameters calculation.

In this work, we present the synthesis of a robust controller with principal gains method. We applied this technique for controlling water levels in a multi-pool open irrigation canal prototype. Design and tests are worked out in simulation on a three-pool open irrigation canal prototype. The basic idea of robust control is to design a controller that provides the stability of the considered nominal operating regime $\mathrm{H} 3$ and disturbed operating regimes $\mathrm{H} 1$ and $\mathrm{H} 2(\mathrm{H} 1, \mathrm{H} 2$ et $\mathrm{H} 3$ are given in section III) and that also ensures a satisfactory level of performance: good response time, static error elimination and no overshoot.

This paper is organized as follows. In section II, the characteristics of the used laboratory canal are presented. Section III gives a brief mathematical description of models of the irrigation canal pools. Section IV presents brief overview of robust control. Section $\mathrm{V}$ gives the details of the robust controller synthesis and in section VI we present our observations and our conclusion

\section{STRUCTURE AND DESCRIPTION OF THE IRRIGATION CANAL}

The geometrical data of the proposed laboratory canal available at IMTA (Mexican Institute of Water Technology) [19] is shortened as follows: it is $50 \mathrm{~m}$ long, $64 \mathrm{~cm}$ wide and $1 \mathrm{~m}$ high The canal is a zero slope rectangular in order to achieve the largest possible time delay, see Figure 1. The slide gates, as control structures, divide the canal in four pools and a servo-valve adjusts the inflow. A manual overshot gate regulates the downstream level of the canal. Each gate operates in submerged condition and is equipped with a linear actuator and two pressure sensors to measure the upstream and downstream levels of the gates, and a potentiometer to sense gate position and limit switches (maximum and minimum gate opening). There are not lateral gates.

As we know, an irrigation canal can be represented as a series of pools, for pool $i$ we denote by $u_{i}$ the control variable (discharge) at the upstream end, $u_{i+1}$ the control variable at the downstream end, $y_{i}$ the controlled variable (water depth at the downstream of pool $i$ ), and $p_{i}$ the load disturbances (water offtake). The control structures in this canal are slide gates and they divide the canal in four pools. The water level corresponding to different flow conditions, the inflow is adjusted with a servo-valve. At the downstream end of the canal, the level is regulated by a manual overshot gate. Each gate is equipped with a linear actuator, two pressure sensors to measure the upstream and downstream levels of the gates, and a potentiometer to sense gate position and limit switches (maximum and minimum gate opening). All gates operate in submerged condition [19]. The input- output system dynamics can be described by a model that can be expressed in the following form: $y(s)=H(s) u(s)$; the transfer function from $u_{i}$ to $y_{j}$ is represented $H_{i j}$ From the level responses $y_{j}$ to a step in gate opening $u_{i}$, it is observed that the canal responses can be reproduced by first order systems, with or without time delay. We also have slight delays due to selected inputs and outputs and physical constraints. 


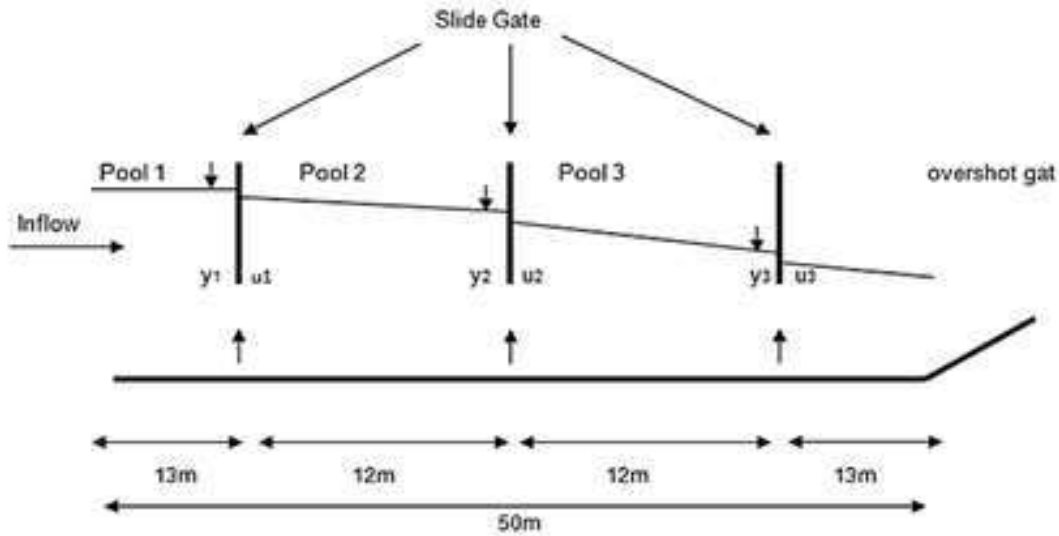

Figure 1. Schematic longitudinal view of the irrigation canal

\section{PROPOSED MODELS}

Linear input-output (I/O) models for designing the controller are derived [18]. This procedure consists in the identification of three transfer matrices, one for each set point signaled in Table 1. Principal gains and condition numbers as shown in Figures 2 and 3.

Table 1. Operating Points

\begin{tabular}{cccccc}
\hline Set point $\mathrm{i}$ & Inflow $\mathrm{Q}(1 / \mathrm{s})$ & Gate opening $\mathrm{u}_{1}, \mathrm{u}_{2}, \mathrm{u}_{3}$ & Level $1 \mathrm{y}_{1}$ & Level $2 \mathrm{y}_{2}$ & Level $3 \mathrm{y}_{3}$ \\
\hline 1 & 80 & 20 & 70.7 & 63.5 & 53.5 \\
2 & 65 & 14.7 & 70.7 & 63.5 & 57.5 \\
3 & 50 & 10.9 & 70.7 & 63.5 & 57.5 \\
\hline
\end{tabular}

The proposed models are given by:

$$
\begin{aligned}
& H_{1}(s)=\left[\begin{array}{ccc}
\frac{0.85}{48 s+1} & \frac{0.625}{168 s+1} & \frac{4.2}{3890 s^{2}+399 s+1} \\
0 & \frac{0.70}{149 s+1} & \frac{4.675}{365 s+1} \\
0 & 0 & \frac{5.12}{326 s+1}
\end{array}\right] \\
& H_{2}(s)=\left[\begin{array}{ccc}
\frac{1.21}{72 s+1} & \frac{0.862}{245 s+1} & \frac{6.806}{5420 s^{2}+552 s+1} \\
0 & \frac{0.93}{216 s+1} & \frac{7.064}{514 s+1} \\
0 & 0 & \frac{7.42}{462 s+1}
\end{array}\right] \\
& H_{3}(s)=\left[\begin{array}{ccc}
\frac{2.04}{84 s+1} & \frac{1.762}{348 s+1} & \frac{10.609}{7150 s^{2}+725 s+1} \\
0 & \frac{1.81}{360 s+1} & \frac{10.739}{691 s+1} \\
0 & 0 & \frac{10.83}{653 s+1}
\end{array}\right]
\end{aligned}
$$

From these three models we present the principal gains of three different flow conditions: 


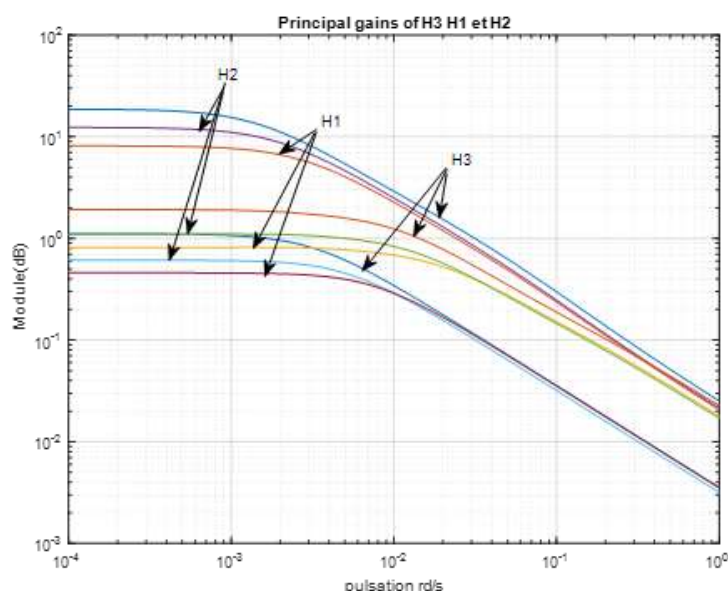

Figure 2. Principal gains

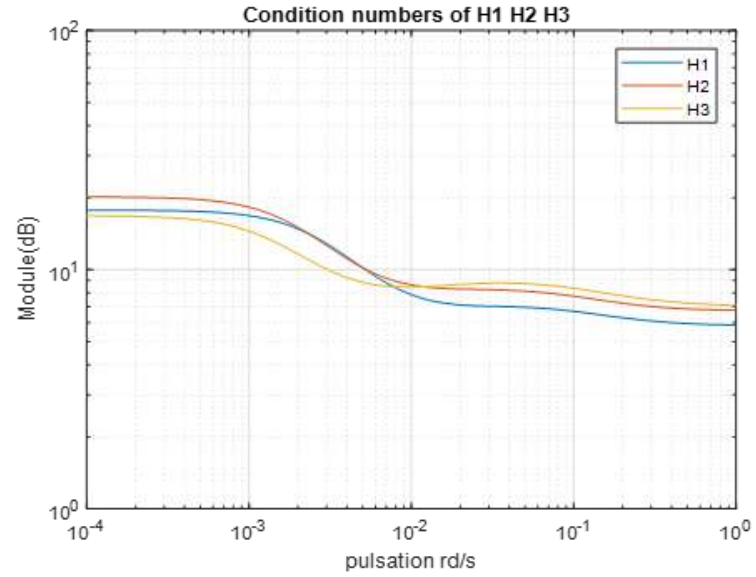

Figure 3. Condition numbers

\section{PRELIMINARIES OF ROBUST CONTROL}

It is necessary to recall the basic required performances of a control loop in the frequency domain. The Figure 4 shows the classical structure of a control loop with the main components: the controller (transfer matrix $\mathrm{K}(\mathrm{s})$ ), the process uncertainty at the process output $\Delta_{m}(s)$, the set-pointr, the loop's error $e$ and finally the manipulated variable $u$ and the output $y$. Let $G^{\prime}(s)$ be the transfer matrix of the true plant, all perturbed regimes. Then the following relation can be written as:

$$
G^{\prime}(s)=\left[I+\Delta_{m}(s)\right] G(s)
$$

The largest singular value of $\Delta_{m}(s)$ is obtained from (1):

$$
\sigma_{\max }\left[\Delta_{m}(s)\right]=\sigma_{\max }\left(\left[G^{\prime}(s)-G(s)\right] G^{-1}(s)\right)
$$

As shown in (2) quantifies the multiplicative models uncertainties.

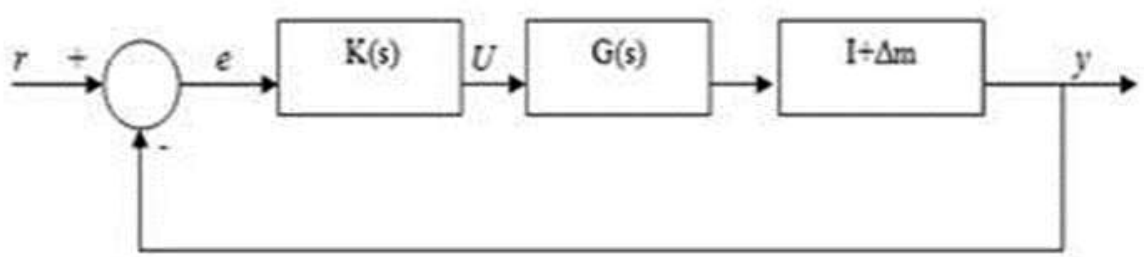

Figure 4. Feedback configuration with multiplicative uncertainties

The model "H3" is considered as a nominal or synthesis model and H1, H2 as considered disturbed operating regimes; the singular values of the multiplicative perturbations at the output are given in Figure 5.

We can observe that in low frequencies these errors do not exceed $100 \%$ below $0 \mathrm{~dB}$, so we can synthesize a robust controller. From this figure we can propose the stability specification:

$$
W_{p}=\left(\begin{array}{ccc}
0.8(1+10 \mathrm{~s}) & 0 & 0 \\
0 & 0.8(1+10 \mathrm{~s}) & 0 \\
0 & 0 & 0.8(1+10 \mathrm{~s})
\end{array}\right)
$$


In fact, the Figure 5 shows the singular values of the maximum disturbance. We chose the performance specifications in such a way that the closed-loop time responses are equal to the open-loop time responses and have a null static error and no overshoot; they are given by:

$$
W_{S}=\left(\begin{array}{ccc}
\frac{1+84 s}{84 s} & 0 & 0 \\
0 & \frac{1+360 s}{360 s} & 0 \\
0 & 0 & \frac{1+653 s}{653 s}
\end{array}\right)
$$

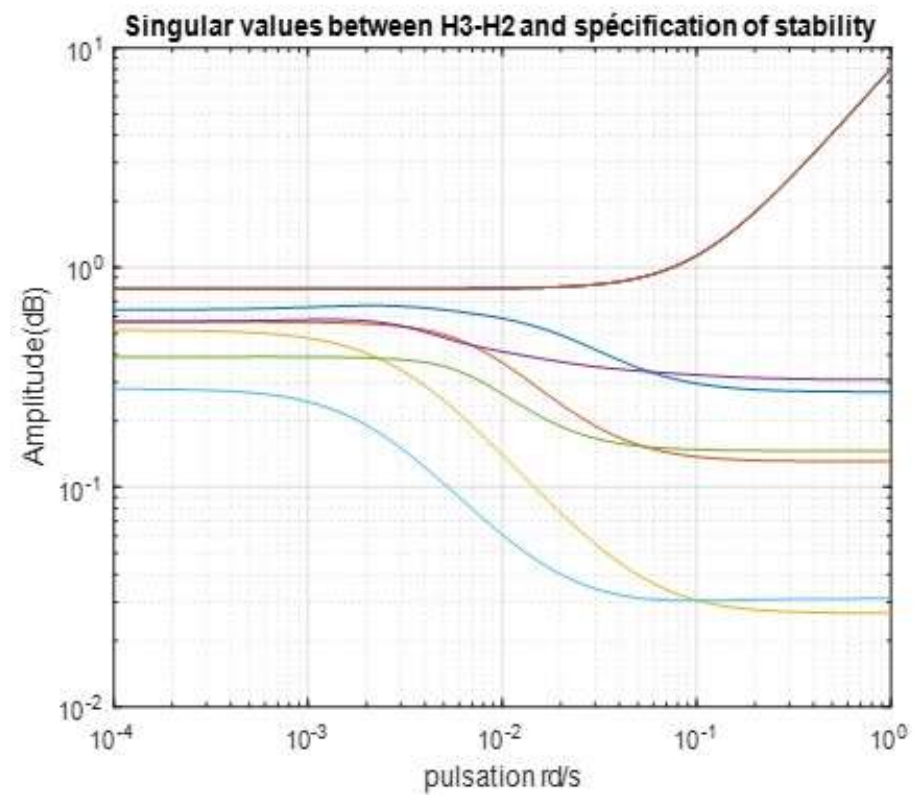

Figure 5. Singular values

\subsection{Robust Stability}

Assume that the nominal feedback system G(s) (i.e. with $\left.\Delta_{m}(s)=0\right)$ is stable, then the true feedback system $\mathrm{G}^{\prime}(\mathrm{s})$ is stable if the following inequality holds (Doyle and Stein, 1981) [21].

$\sigma_{\max }[T(s)]<1 /\left[\sigma_{\max } W_{t}(s)\right]$

Where $\mathrm{T}(\mathrm{s})$ is the nominal closed loop transfer matrix, it is given by:

$T(s)=G(s) K(s)[I+G(s) K(s)]^{-1}$

$W_{t}(s)$ is a stability specification matrix such as:

$\sigma_{\max }\left[\Delta_{m}(s)\right] \leq \sigma_{\max }\left[W_{t}(s)\right]$

$\sigma_{\max }[T(s)]$ Is the largest singular value of the nominal closed loop transfer matrix, it is a reliable indicator of feedback system robust stability [22]. Then the robustness condition of the feedback system is given by (3).

\subsection{Robust Performance}

Let $W_{p}(s)$ a performance specification matrix, weighting matrix, then the robust performances of all perturbed regimes $\mathrm{G}^{\prime}(\mathrm{s})$ are satisfied if the following inequality holds [21-23]:

$$
\sigma_{\max }[S(s)] \leq 1 / \sigma_{\max }\left[W_{p}(s)\right]
$$


Where $S(s)$ is the sensitivity matrix given by:

$S(s)=[I+G(s) K(s)]^{-1}$

The robustness conditions for stability and performances are given by (3) and (6). They are shown in Figure 7. The specifications on stability and performance are given in Figure 6.

In fact, the largest singular value of the sensitivity matrix $\sigma_{\max }(S)$ is also an indicator of the sensitivity of the system response to a change on the plant characteristics. In conclusion, the inequalities (3) and (6) represent the robustness conditions and must be satisfied to obtain a robust controller.

The condition for robust performance is given by (6) and the robustness conditions for irrigation main canal pools are represented in Figure 8.

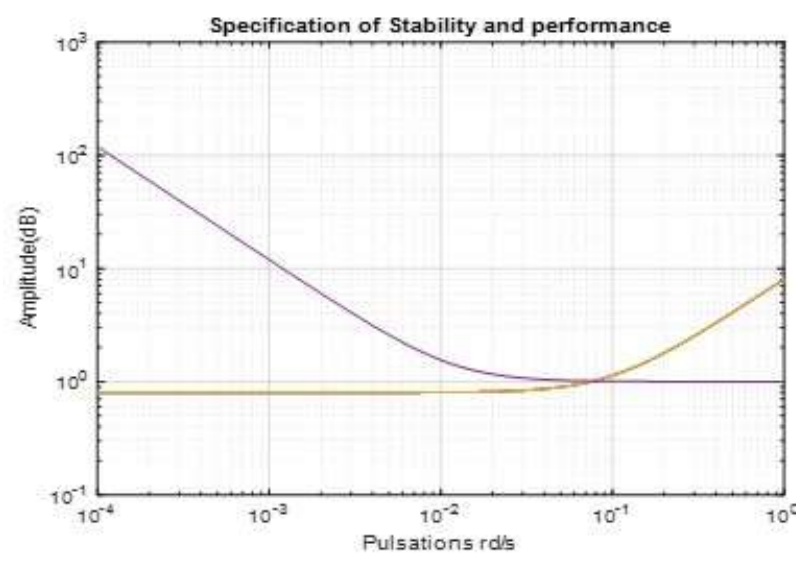

Figure 6. Robustness conditions

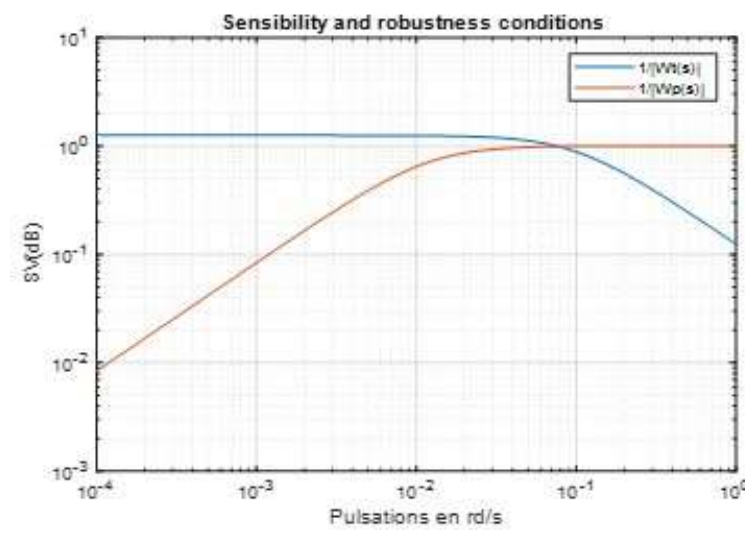

Figure 7. Robustness conditions

\section{ROBUST CONTROL DESIGN}

The principal gains method consists of finding a controller $K(s)$ given by (8) such that (9) is satisfied and the conditions (3) and (6) for robust stability and performance are also verified.

The principal gains method is based on finding a controller with the following structure [24]:

$$
K(s)=K 1 * K 2(s) * K 3 * K 4(s)
$$

where:

$K 1=G^{-1}(0)$ is the inverse static gain: It is used to decouple the process in low frequency; $K 2(s)=\frac{1}{s}$ is a set of integrators to eliminate the static error.

$K 3$ is a compromise coefficient between the stability and performances.

$K 4(s)$ is a structure to reduce the resonance magnitude in middle and high frequency; In order to not affect the controller in low frequency, we have to set $K 4(0)=I$, this can be obtained by minimization of the following criteria [17]:

$$
\min K 4(J)=\min K 4 \max w\left[\sigma_{\max }(T) \sigma_{\max }\left(\Delta_{m}\right)\right]
$$

Where: $\sigma_{\max }(T) \times \sigma_{\max }\left(\Delta_{m}\right)$ is a stability robust condition.

\subsection{Robust Controller with Principal Gains Method}

The principal gains method consists of finding a controller K(s) given by (8) such that the condition in the (9) is satisfied and the conditions in (3) and (6) for robust stability and performance are also verified. A nominal model used in the design is defined by: 
$H_{3}(s)=\left[\begin{array}{ccc}\frac{2.04}{84 s+1} & \frac{1.762}{348 s+1} & \frac{10.609}{7150 s^{2}+725 s+1} \\ 0 & \frac{1.81}{360 s+1} & \frac{10.739}{691 s+1} \\ 0 & 0 & \frac{10.83}{653 s+1}\end{array}\right]$

The obtained controller: $K 1=G^{-1}(0)=\left[\begin{array}{ccc}0.4902 & -0.4772 & -0.0070 \\ 0 & 0.5525 & -0.5478 \\ 0 & 0 & 0.0923\end{array}\right]$

The structure K1 serves to decouple the system at low frequencies, indeed the following figure illustrates in Figure 8. The effect of integrator set K2 (s) is given in the Figure 10 and Frequency results as shown in Figure 9.

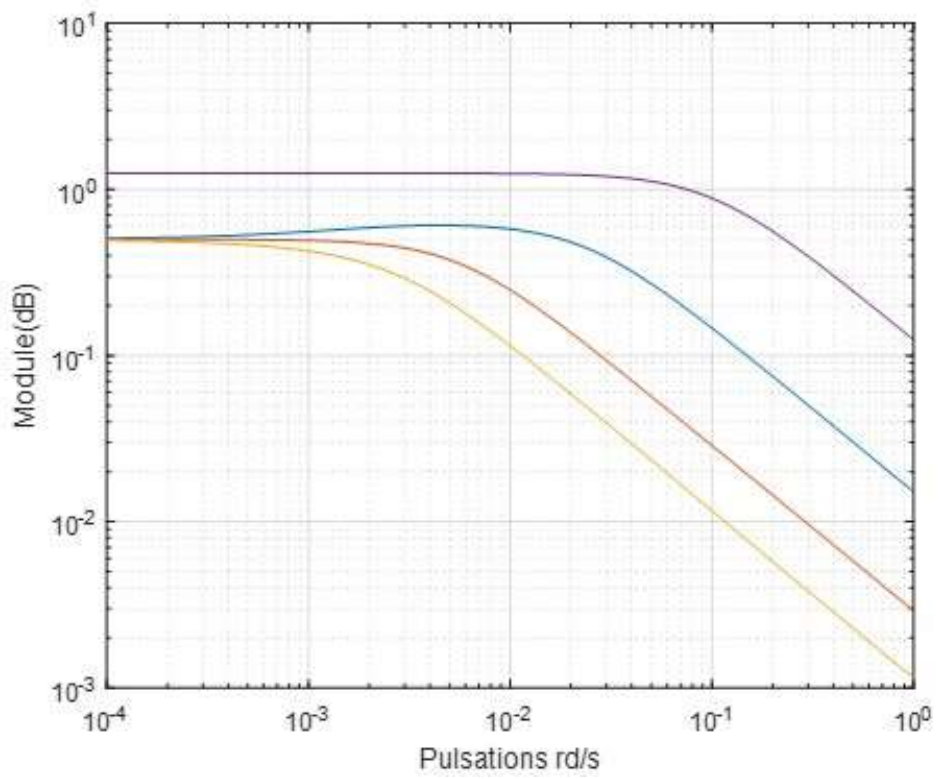

Figure 8. Feedback principal gains

$$
K 2=\left[\begin{array}{ccc}
\frac{1}{s} & 0 & 0 \\
0 & \frac{1}{s} & 0 \\
0 & 0 & \frac{1}{s}
\end{array}\right]
$$

We can observe the decoupling at low frequency up to 10-2 as well as a null static error.

We can also see the appearance of mid-frequency resonance peaks of 10-2 up to 10-1 which will be eliminated by the K4 structure.

$$
\left[\begin{array}{ccc}
k_{11} s+1 & k_{12} s & k_{31} s \\
0 & k_{22} s+1 & k_{23} s \\
0 & 0 & k_{33} s+1
\end{array}\right]
$$

Where the obtained ${ }^{k_{i j}}$ values are: 653;

$$
\mathrm{k}_{11}=84 ; \mathrm{k}_{12}=265,9 ; \mathrm{k}_{13}=390,5 ; \mathrm{k}_{21}=\mathrm{k}_{31}=\mathrm{k}_{32}=0 ; \mathrm{k}_{22}=360 ; \mathrm{k}_{23}=310.2 ; \mathrm{k}_{33}=
$$

Are obtained by the minimization of the criterion given in $(9)$; the coefficient value $(\mathrm{K} 3=0.03)$ is obtained by the simulation [25], in order to adjust the compromise between stability and performance. 
Finally, we can give the overall global controller of the (8) as follows:

$$
K=\left[\begin{array}{ccc}
\frac{1.235 s+0.01471}{s} & \frac{-1.243 s-0.01432}{s} & \frac{1.165 s-0.0002102}{s} \\
0 & \frac{5.967 s+0.01657}{s} & \frac{-5.591 s-0.01644}{s} \\
0 & 0 & \frac{1.809 s-0.00277}{s}
\end{array}\right]
$$

The Figure 11 illustrates the results in frequency domain where we can observe that the robustness conditions are not violated; the stability is guaranteed if the largest singular value of closed loop transfer matrix function $\left(\sigma_{\max } T(s)\right)$ is lower than the upper bound of the largest singular value of the model uncertainties $\left(1 /\left[\begin{array}{ll}\sigma_{\max } & W_{t}(s)\end{array}\right]\right)$. The same idea is used for the robust performance criterion.

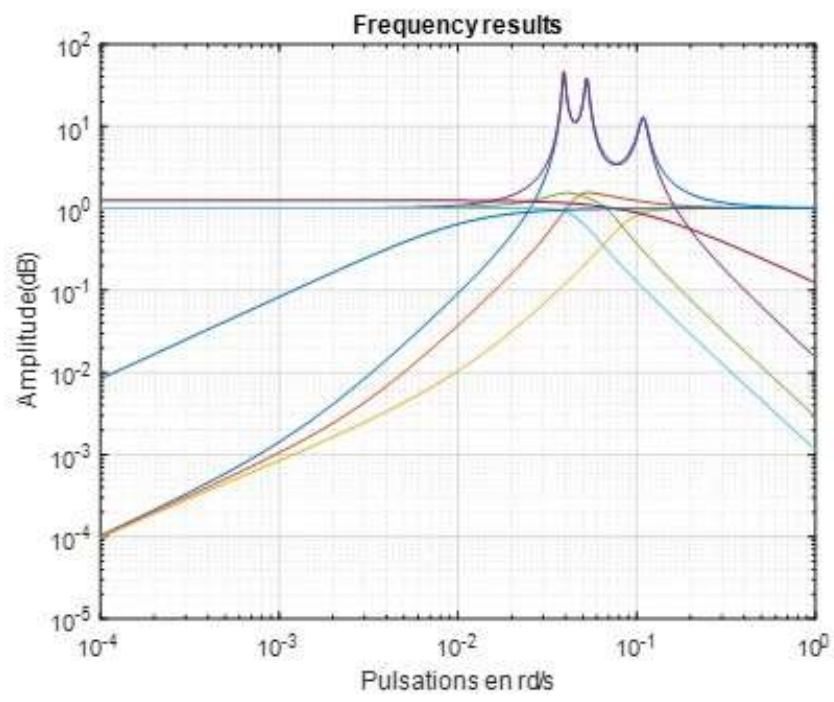

Figure 9. Frequency results

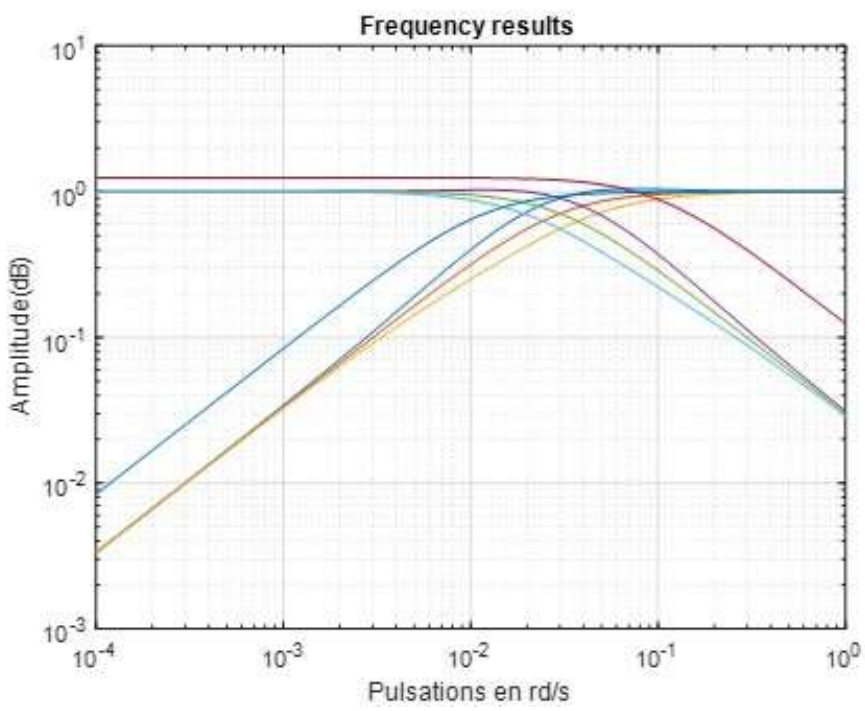

Figure 10. Frequency results

The step and impulse responses given in the three following figures, they show that the stability and the good performance are realized with strong attenuations of the interactions (weak coupling). 


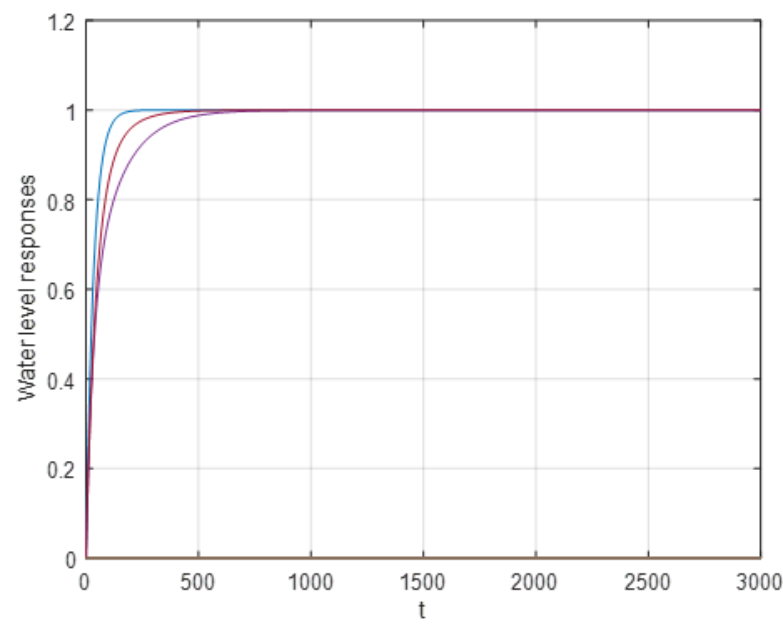

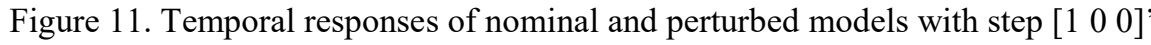

Temporal responses of nominal and perturbed models with step [0 $\left.\begin{array}{lll}0 & 1 & 0\end{array}\right]$ and $\left[\begin{array}{lll}0 & 0 & 1\end{array}\right]$ as shown in Figure 12-13.

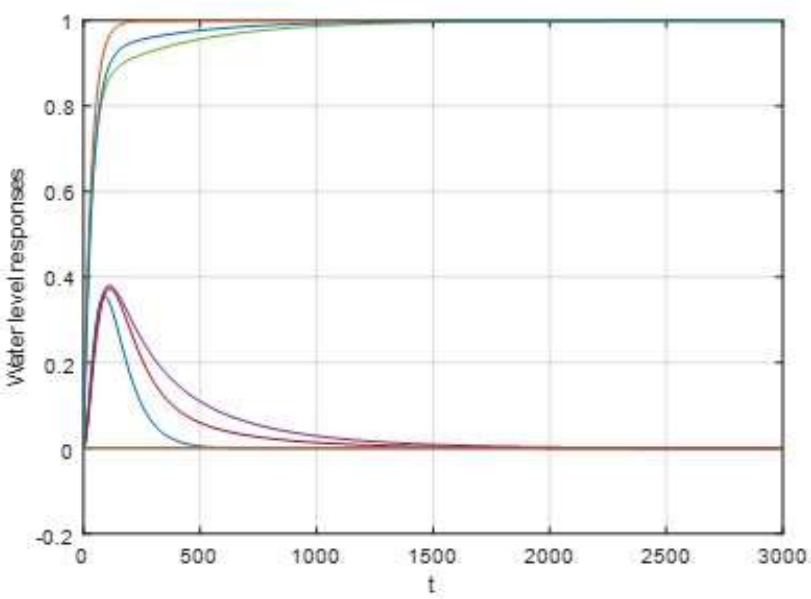

Figure 12. Temporal responses of nominal and perturbed models with step [ $\left.\begin{array}{lll}0 & 1 & 0\end{array}\right]$

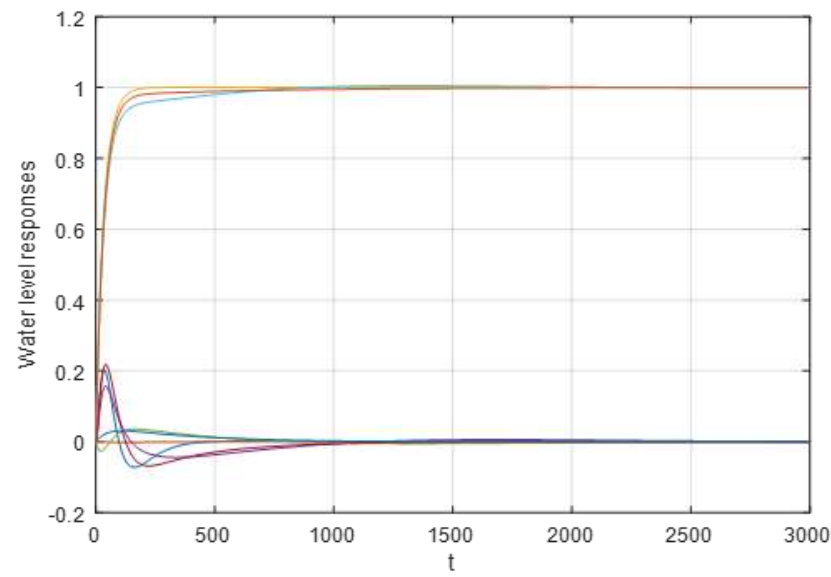

Figure 13. Temporal responses of nominal and perturbed models with step [0 $\left.\begin{array}{lll}0 & 0 & 1\end{array}\right]$ ' 


\section{CONCLUSION}

In this paper, we have presented, applied and validated an efficient automatic controller for a multipool open irrigation canal prototype in order to regulate the water level at the downstream end of each pool to a specified reference value, under inflow disturbances. The controller in question is more robust than standard PI controllers to high frequency noises and modeling inaccuracies. In irrigation canal pools, the dynamics strongly change with the discharge regime variations. The adopted robust control strategy involves a robust controller with principal gains method ensuring stability, robustness and performance. The robustness properties of this controller have been justified theoretically in a qualitative way. The interest of such controllers is justified by the fact that dynamical parameters of irrigation canal pools may change considerably in function of its operation regimes. Simulations in Matlab environment have been carried out in a multi-pool irrigation canal prototype at IMTA (Mexican Institute of Water Technology). These simulations showed the appreciable performance and robustness of this controller. Finally, we have to mention that the employed linear models obtained by identification are simple and we must know if they really reflect all complex phenomena of operational canals such as slope changes, frictions, etc. Therefore, the use of these models could be reconsidered in future work.

\section{REFERENCES}

[1] De Oliveira, J.B. et al. "Optimized Fractional Order Sliding Mode Controller for Water level in irrigation canal pool" IFAC 7663-7668, 2017.

[2] Litrico, X. and Fromion V. "Modeling and control of hydro-systems." Springer, 2009.

[3] A. J. Clemmens et al. "Control of Irrigation Canal Networks" Journal of Irrig and Drai Eng Vol. 115, Issue 1, February 1989.

[4] Sepúlveda Toepfer, C. A. "Instrumentation, model identification and control of an experimental irrigation canal", Doctoral Thesis, 2007.

[5] Begovich, O. et al. "Predictive control with constraints of a multi-pool irrigation canal prototype", Latin American Applied Research 37, 177-185, 2007.

[6] Litrico, X. and Fromion V. "Frequency Modeling of Open-Channel Flow", Journal of hydraulic engineering; Vol. 130, No. 8. ISSN 0733-9429, 2004.

[7] A.J. Clemmens and J. A. Replogle "Control of Irrigation Canal Networks" Journal of irrigation and drainage engieneering V.115 issue1, February 1989

[8] Litrico, X. and Fromion, V. "Simplified modelling of irrigation canals for controller design". Journal. Irrig. Drain. Eng., 130(5):373-383, 2004b.

[9] Malaterre, P.O. and Rodellar J. "Multivariable predictive control of irrigation canal: design and evaluation on a 2pool model", Proceedings of the International Workshop on Regulation of Irrigation Canals, Morocco, 230-238, 1997.

[10] Besançon, G. et al. "First experimental results of nonlinear control in irrigation canals", Second IFAC Symposium on System, Structure and Control "SSSC2004", Oaxaca, México, 2004.

[11] Eurén, K. and Weyer E. "System identification of open water channels with undershot and overshot gates", 16th IFAC World Congress, Prague, Czech Republic, 2005.

[12] Begovich, $\mathrm{O}$ et al. "Real-time application of a fuzzy gain scheduling control scheme to a multi-pool open irrigation canal prototype", Journal of Intelligent \& Fuzzy Systems, 16, 189-199, 2005.

[13] Litrico, X. and Fromion V. "Design of Structured Multivariable Controllers for Irrigation Canals", Proceedings of the 44th IEEE Conference on Decision and Control, and the European Control Conference 2005 Seville, Spain, December 12-15, 2005.

[14] Sánchez, L. et al. "Robust Control of a Laboratory Hydraulic Canal by Using a Fractional PI Controller", International Design Engineering Technical Conferences and Computers and Information in Engineering Conference. Vol. 5, 1307-1315, 2007.

[15] Rivas-Perez, R. et al. "Control-oriented model of a complex irrigation main canal pool". In: IFAC Proceedings Volumes IFAC-Papers Online 2919-2924, 2011.

[16] Aguilar, J.V. et al. "Predictive control of irrigation canals-robust design and real-time implementation" International Journal of Water Resources Management Springer, Volume 30, Issue 11, pp 3829-3843, 2016.

[17] R. Rivas-Perez et al. "Mathematical model for robust control of an irrigation main canal pool" Elsevier ISSN: 1364-8152, 2014.

[18] Begovich, O., Martinez, E. and Ruiz, V.M. "Decentralized Fuzzy Gain Scheduling Control for an Open Irrigation Canal Prototype". 4th International Conference on Electrical and Electronics Engineering, ICEEE 2007. 262-265, 2007.

[19] Begovich, O., Felipe, J.C. and Ruiz V.M. "Real-time implementation of a decentralized control for an open irrigation canal prototype", Asian Journal of Control, Vol. 9, No. 2, pp. 170-179, 2007.

[20] V. Feliu-Batlle et al. "Fractional order controller robust to time delay variations for water distribution in an irrigation main canal pool" Journal of Computers and Ekectronics in Agriculture Elsevier. ISSN:0168-1699, 2009.

[21] Doyle, J C. and Stein G. "Multivariable Feedback Design: Concepts for a Classical Modern Synthesis" IEEE. Trans. Automat. Control, vol.AC26, N¹, pp.4-16, 1981. 
[22] U.Mackenroth. "Robust Control Systems Theory and Case Studies" Springer book, 2004.

[23] Safonov, M.G. and Chiang R.Y. "CACSD using the State Space L ${ }^{\infty}$ Theory -A Design", Trans.Automat. Control. AC33, No5, pp.477-479, 1988.

[24] Merabti, N., Arbaoui F. and Yahmedi S. "Robust Control for Irrigation Canals", International Journal of Scientific Research \& Engineering Technology (IJSET) vol.1, pp59-63, 2014.

[25] D.Gu, P.Petkov, and M. Konstantinov. "Robust Control Design with Matlab. Springer, 2005.

\section{BIOGRAPHIES OF AUTHORS}
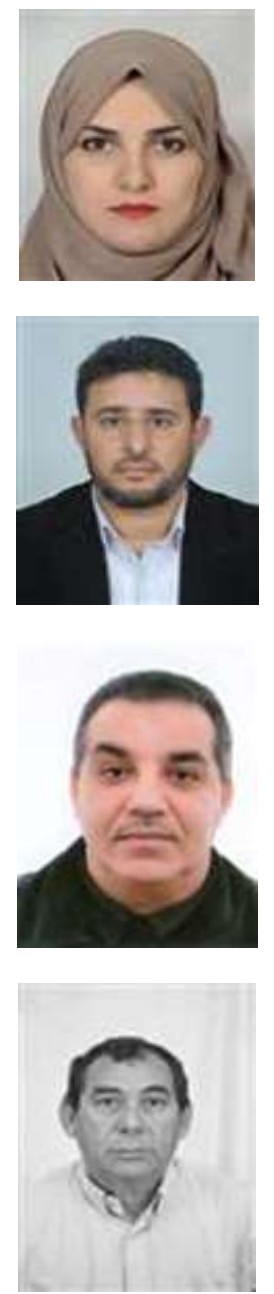

Nardjes Merabti was born in Annaba (Algeria), in 1988. She received The B.S. degree in 2008 and M.S. degree in 2010 in automation engineering from the University of Annaba. Since 2011 she is currently pursuing the $\mathrm{PhD}$ degree in Automation engineering at Badji Mokhtar Annaba University. E-mail address : nardjes.merabti@univ-annaba.org

Fayçal Arbaoui was born on June $9^{\text {th }}, 1966$ in Annaba (Algeria). He graduated from the Badji Mokhtar university (BMU) in Annaba, and received the $\mathrm{PhD}$ degree in automatic control in 2006. He is teaching Automatic control since 1992 as an Associate Professor at Electronics Department of the BMU University. His research focuses on intelligent automatic control, fault diagnosis and fault tolerant control, especially in the fields of electric machines, windpower and irrigation canals. E-mail address: arbaoui @univ-annaba.org

Mohammed Larbi SAIDI was born in Annaba (Algeria), on March 29 $9^{\text {th }}$, 1966. He graduated the Badji Mokhtar University, Faculty of Engineering in Annaba (Algeria), in 1990. He received the $\mathrm{PhD}$ degree in Automation from the Badji Mokhtar University of Annaba (Algeria), in 2006. He is Associate Professor at Electronics Department of Badji Mokhtar University, in Annaba (Algeria). His research interests concern: Control systems, electric machines, and windpower. Email address: mohamed-larbi.saidi @univ-annaba.dz

Said Yahmedi Was born on February 7, 1951in Guelma Algeria. He received The Diplome d'Ingénieur en Electronique from the Ecole Nationale Polytechnique d'Alger in 1979, the M.S degree in Automatic control from Université d'Annaba in 1988 and the Ph.D degree in Electrical engineering from Université Laval, Quebec, Canada in 1993. He has been with the department of Electronic at the University of Annaba Algeria since 1981 where he is presently professor of automatic control. His research interests are focused in robust control and its applications to multivariable systems. E-mail address: saidyahmedi@yahoo.fr 